\title{
Effect of the gamma Radiation on Vegetative Development of the Native Grapevine (Vitis
} vinifera $L_{.}$) in morocco

\author{
El oualkadi Aicha ${ }^{1}$, Hajjaj Badr ${ }^{1}$, Mouhib Mohammed ${ }^{1}$, Sbaghi Mohammed ${ }^{2}$
}

${ }^{1}$ INRA- Regional Agricultural Research Center of Tangier, Morocco

${ }^{2}$ INRA- Regional Agricultural Research Center of Rabat, Scientific Division, Rabat, Morocco

Corresponding author E-mail: ai.oualkadi@gmail.com

\begin{abstract}
This study was conducted at the Larache experimental field, CRRA Tangier. For the discrimination of irradiated and control grapevines, 14 characters and 10 replicates for each parameter were used for this study according to the OIV code. The characters were evaluated in different organs of the plant, the twig and the mature leaves. The results showed a differentiation between irradiated and control grapevines. $23 \%$ of the irradiated grape varieties had a drop branch while only $3 \%$ of the control varieties showed this type of branch. $7 \%$ of the irradiated grape varieties showed a copper coloring of the upper face of the leaf whereas no control plant showed this coloration. $40 \%$ of the irradiated grape varieties showed a slightly longer petiole compared to the median vein in comparison with $7 \%$ of the control varieties having the same character. $43 \%$ of irradiated grape varieties showed a tooth shape with a mixture of two straight sides and two convex sides while most control grapes (57\%) showed a tooth shape with two straight sides. It was also observed that some irradiated grape varieties (10\%) showed the shape of the superior lateral sinus with slightly overlapping lobes and 3\% of the irradiated grape varieties showed a form of the lateral sinus superior very widely open while the latter two forms are absent in groups of control grapevines. The irradiated grape varieties showed a higher density of main hairs compared with irradiated grape varieties. For the qualitative parameters it has been observed that the length of the teeth in the irradiated plants is never very short whereas in the control plants the length can be short and very short. The length of the tendrils and the length of the internodes are higher in the irradiated plants than in the control plants.
\end{abstract}

Keywords-Grapevine, Gamma irradiation, qualitative parameters, quantitative parameters, Morocco.

\section{INTRODUCTION}

The traditionally grown grapevine belongs to the species Vitis vinifera $L$. It is a remarkable agronomic species, steeped in history and symbols, and offering exceptional diversity [1]. Grapes, Vitis vinifera $L$ are widely distributed in the tropics and subtropics with ranges extending into the temperate regions [2]. Grape occupies the first position among the fruits in the world in terms of area and production [3]. The world area occupied by grape is 7.63 million hectares producing 64.29 million tons per annum [4]. The cultivated grapevines differ from each other in the appearance of their foliage and clusters; they make up what grapevine growers call grape varieties and botanists of cultivars. The correct identification of grape varieties or hybrids is based essentially on the morphology of all vegetative organs. The description of the varietals is necessary for the establishment, a description code containing the definition of botanical terms used for a good international understanding. In 1951, the
International Office of Vine and Wine published an ampelographic vocabulary, which served as a basis for the drafting of the "International Ampelographic Register". Study of morphology of plants, bud and morphology of grapes is the first way to detect grapevine cultivars especially during in situ collection of plants $[5,6,7,8]$ and establishment of relationships between grapevine cultivars and resolution of different classification problems [9]. Many studies have been used for the identification of grapevine varieties $[10,11,12]$. Like other plants of agronomic interest such as lemon or coffee, clonal diversity in the grapevine is very important [13]. Although conserving the general varietal characteristics, the clones can be distinguished from each other by specific ampelographic characters. In the vineyard, this clonal diversity is of major importance for growers since it allows a varietal improvement without changing grape identity in accordance with the regulations set by the Protected Designations of Origin. 
In Morocco, the grapevine is one of the oldest cultures, it has known in the past important wine areas. Currently the Table 1 Studied character requirement of grape was fulfilled througk theimdert fromaracters other countries using hard carned foreigncuronkiog as thBranch: port demand is increasing with the increase irompopylationyoung sheet: color of the higher face Despite this decline, viticulture occupies 3 faidMvowprtanBreak into leaf adult: form limb place in the Moroccan socio-economic l\&veloftrogyriet\$reak into leaf adult: length of the petiole compared to the length of the median spectrum of the national table grapsinervo 7 mostl Break into leaf adult: form teeth composed of very old local grapes, dominateddivĐorkkkaBreak into leaf adult: length of the teeth and Abbou and the rest is occupied by forqign 7grapBranch: length of the gimlets varieties strongly represented by Valeigcy @id 3 Whiscatiranch: length of the entrenoeuds [14]. The improvement projects of the grapeygne iBreak into leaf adult: general form of the petiolar sine

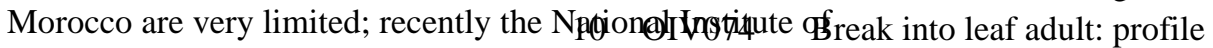

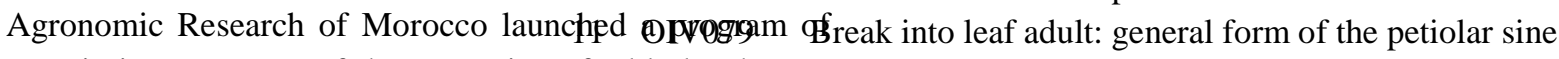
genetic improvement of the grapevine of 2 tabdor of induced mutagenesis. An adequate dqs9 ofgamosa raysreak into leaf adult: density of the hairs laid down between the veins for mutation induction has recently been 4 defögdo 8 y [15Break into leaf adult: density of the drawn up hairs of the principal veins Including this objective a set of table grape mutants installed in the INRA Larache grapevine collection was studied in order to see if there is a phenotypic difference between the irradiated and control grapevines.

\section{MATERIEL AND METHODES}

The vegetative material consists of irradiated and control grapevines planted at the Larache experimental station. We tried to study a set of qualitative and quantitative parameters of the irradiated grapevines and compared them with the control plants. A total of 15 characters and 10 repeats for each parameter were used for this study. The traits were evaluated in different plant organs, the branch and young leaves and mature leaves (Table 1). The ampelographic characters have been described using the OIV descriptors [16, 17]. The main component analysis was carried out by SPSS software ${ }^{\circledR}$ version 20.0.

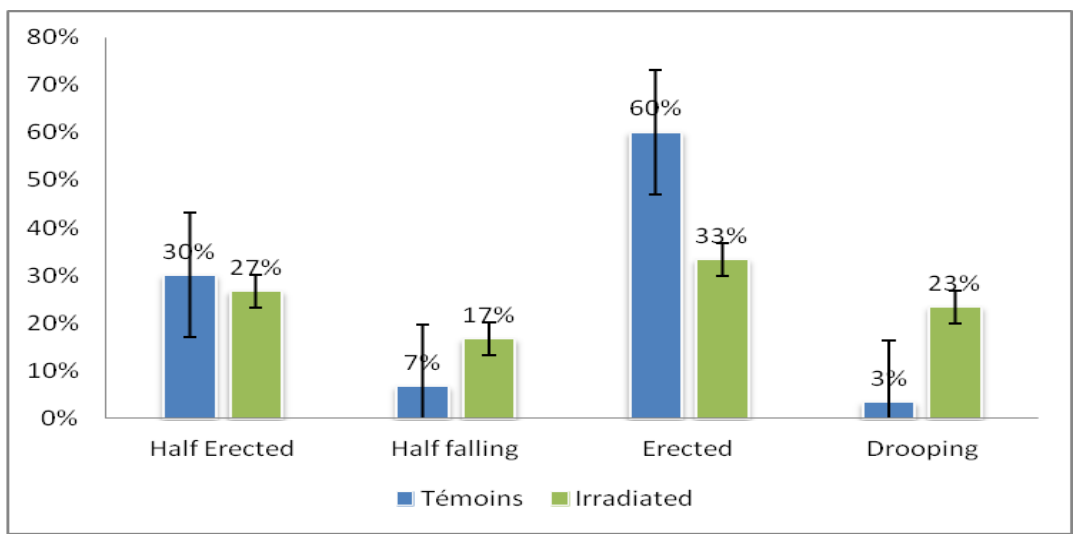

Fig.1. Distribution of branch port in control and irradiated groups

\section{RESULTS AND DISCUSSION}

\section{Qualitative characteristics of the young shoot}

\subsection{Branch port}

The following figure represents the distribution of the percentage of the port of the grape varieties of the control and irradiated groups of the grapevine; one notices that $17 \%$ of the irradiated grape varieties presented a port of the semi-drooping shoot, whereas only $7 \%$ of the control grape varieties showed the same type of port of the branch. Also, 23\% of the irradiated grape varieties had a drop branch while only $3 \%$ of the control varieties showed this type of shoot. However, most of the $60 \%$ control varieties showed a type of erect branch.

\section{Qualitative characteristics of the young leaf}

\subsection{Color of the upper side of the leaf}

The leaves have all the terms of passage from pale green to dark green and their color is accentuated by age. If theoretically differences in hues can be sufficient to distinguish certain grape varieties, practically it is impossible to establish a correct scale whose interpretation can vary with the observer. In autumn the 
grapevines are generally yellowish in color. However, the dyes and some varieties become naturally reddish.

The color distribution of the upper face of the leaf is shown in Figure 2. We notice six classes of the color of the upper face of the leaf. The three classes such as the yellow, yellow and red color of the upper face of the leaf are almost homogeneous for both control and irradiated grapevine. Whereas for the green color of the upper surface of the leaf we saw $33 \%$ of the control grape varieties against this coloration against $23 \%$ of grape varieties irradiated since the same coloration. $30 \%$ of irradiated varieties showed a green color with tanned beaches of the upper face of the leaf against $23 \%$ these grape varieties are witnesses of the same coloring. We observed $7 \%$ of irradiated grape varieties on a copper coloring of the upper surface of the leaf.

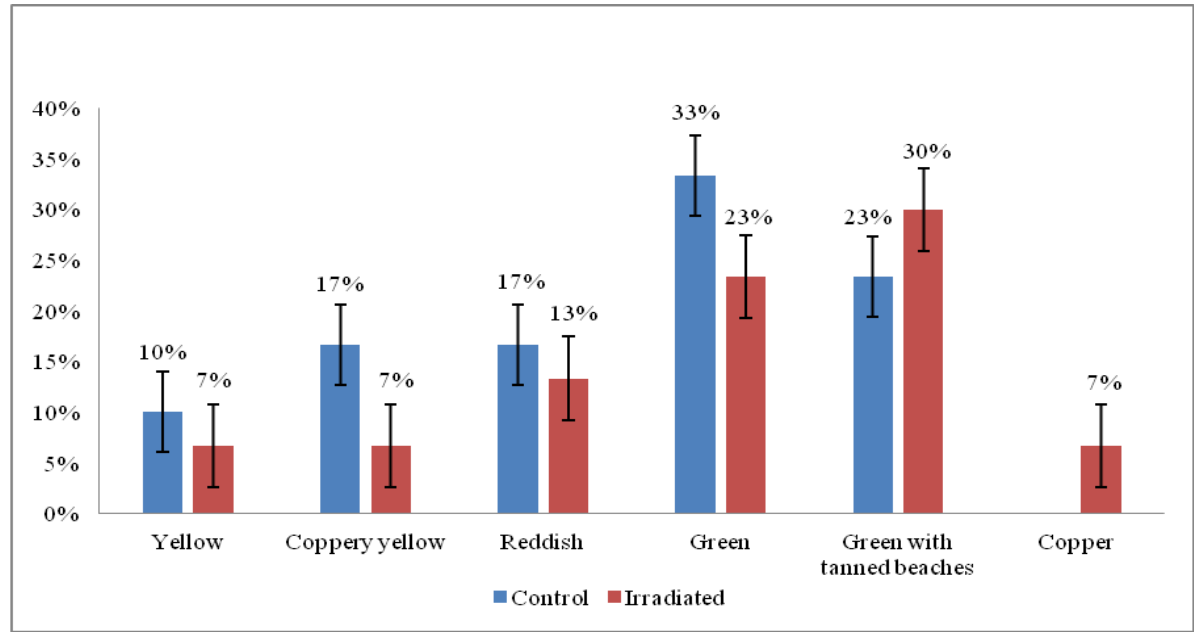

Fig.2. Distribution of upper leaf color in control and irradiated grapevine groups

\section{Qualitative characteristics of the mature leaf}

\subsection{Shape of the limb}

The appearance of the surface of the limb is a secondary character, but it can sometimes modify so much the foliage, that the latter then takes a characteristic appearance. The shape of the limb varies in five groups according to Figure 3. We note that most irradiated and control grape varieties showed a wedge-shaped shape. An almost homogeneous distribution of the other classes of the limb shape was observed in both control groups and irradiated.

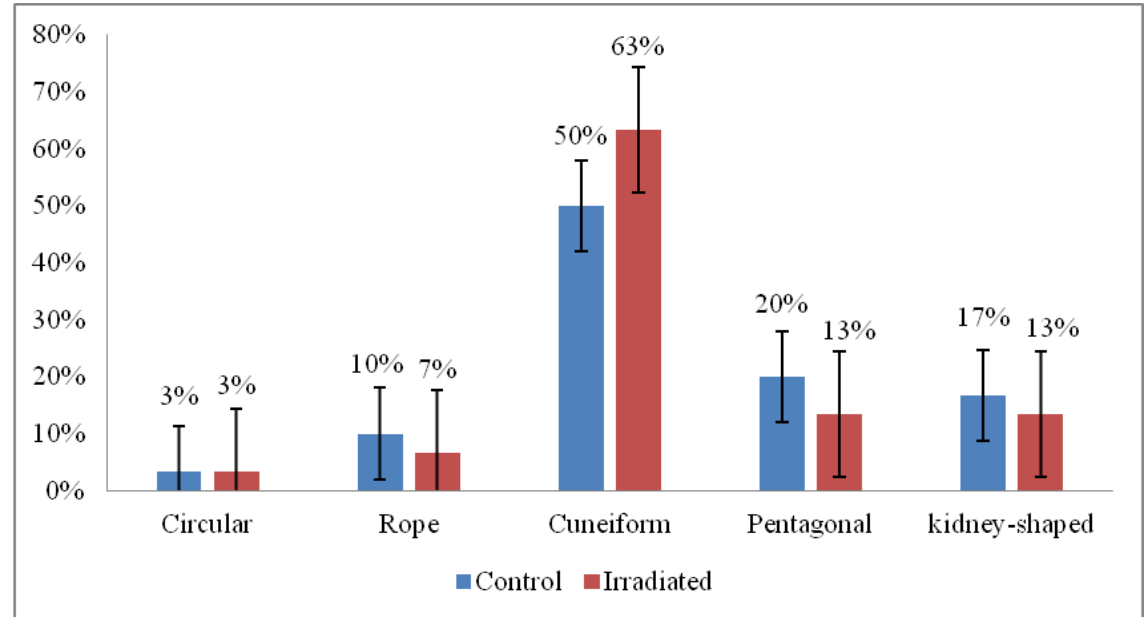

Fig.3. Distribution of the limb shape in the group of irradiated and control grapevines.

\subsection{Length of the petiole compared to the length of the midrib}

The distribution of the petiole length in relation to the midrib is shown in Figure 4. From the figure we observed that $40 \%$ of irradiated grape varieties showed a slightly longer petiole compared to the midrib in comparison with $7 \%$ of the control varieties that showed a longer petiole. $33 \%$ of the control and irradiated varieties have the length of the petiole is equal to the length of the midrib. 


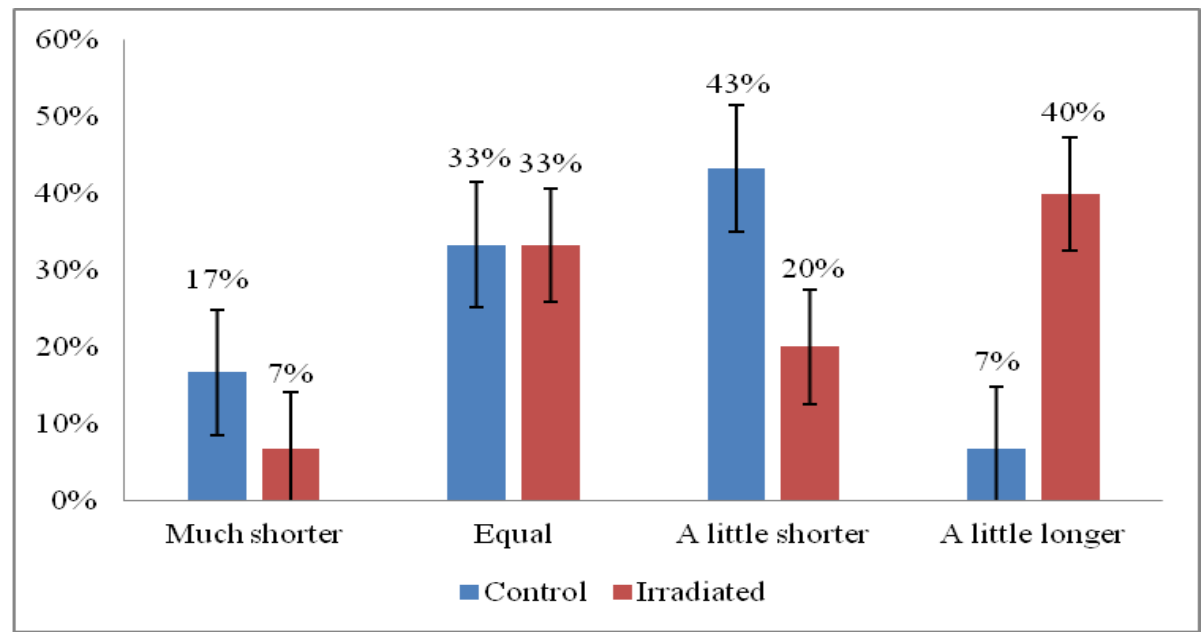

Fig.4. Distribution of the petiole length compared to the median vein

\subsection{Tooth shape}

The serration is a very good visual ampelographic character, unfortunately very difficult to code, because the same leaf is found with different shaped teeth and unequal depth. By analyzing Figure 5 we note that $43 \%$ of irradiated grape varieties showed a tooth shape with a mixture of two straight sides and two convex sides. Also, $23 \%$ of the irradiated grape varieties showed a tooth shape with a concave side and a convex side compared to $57 \%$ of the control grape varieties showed a tooth shape with two straight sides.

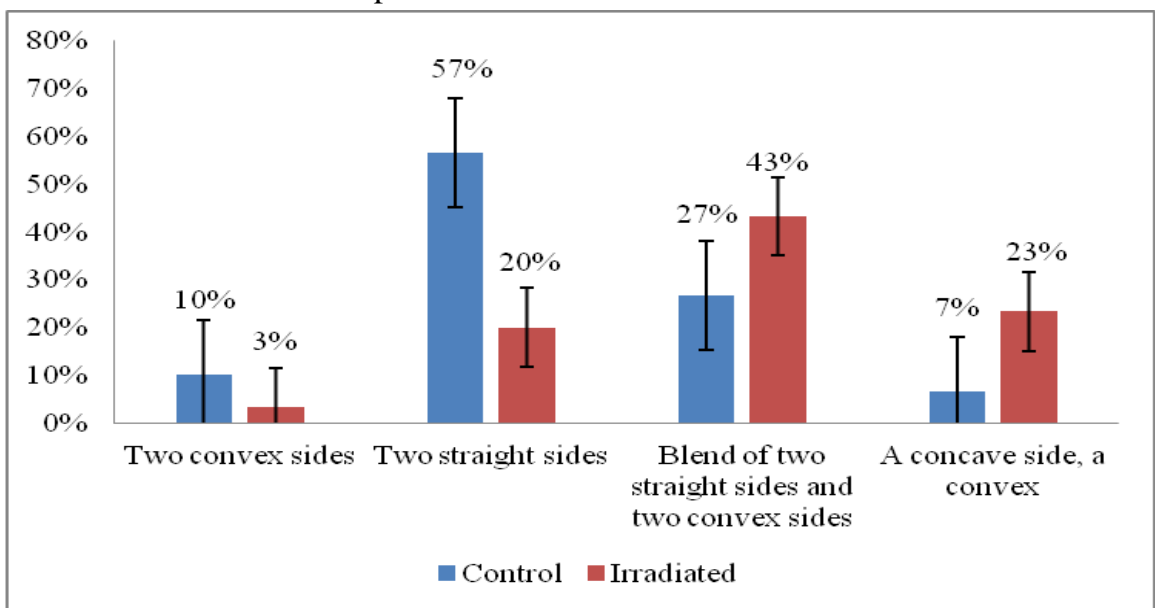

Fig.5. Shape of the teeth in the grapevines of the control and irradiated groups

\subsection{Degrees of opening or sinus overlap}

The petiolary sinus often makes an important contribution in the ampelographic distinction. Its shape is at the sum of the angles of the ribs, that is to say $\Sigma$. The shape of the sinus is variable. When they are shallow or almost void, they are often in the form of a deep V. They affect particular forms according to whether the bottom of the sinus is concave or acute. Similarly both sides of the sinus can remain substantially parallel (in glove finger). The shape of the upper lateral sinuses influences the aspect of the medial lobe of the leaf. While in whole or weakly cut leaves, it is broad, compact not detaching from the limb on the contrary in the grape varieties with deep upper lateral sinuses, the median lobe is more or less narrowed, sometimes giving a pace "wasp size" .

The following figure shows the general shape of the petiolar sinus. We note that $82 \%$ of irradiated grape varieties have a wide open petiole sinus. Also $3 \%$ of irradiated grape varieties showed a petiole sinus very widely open. 


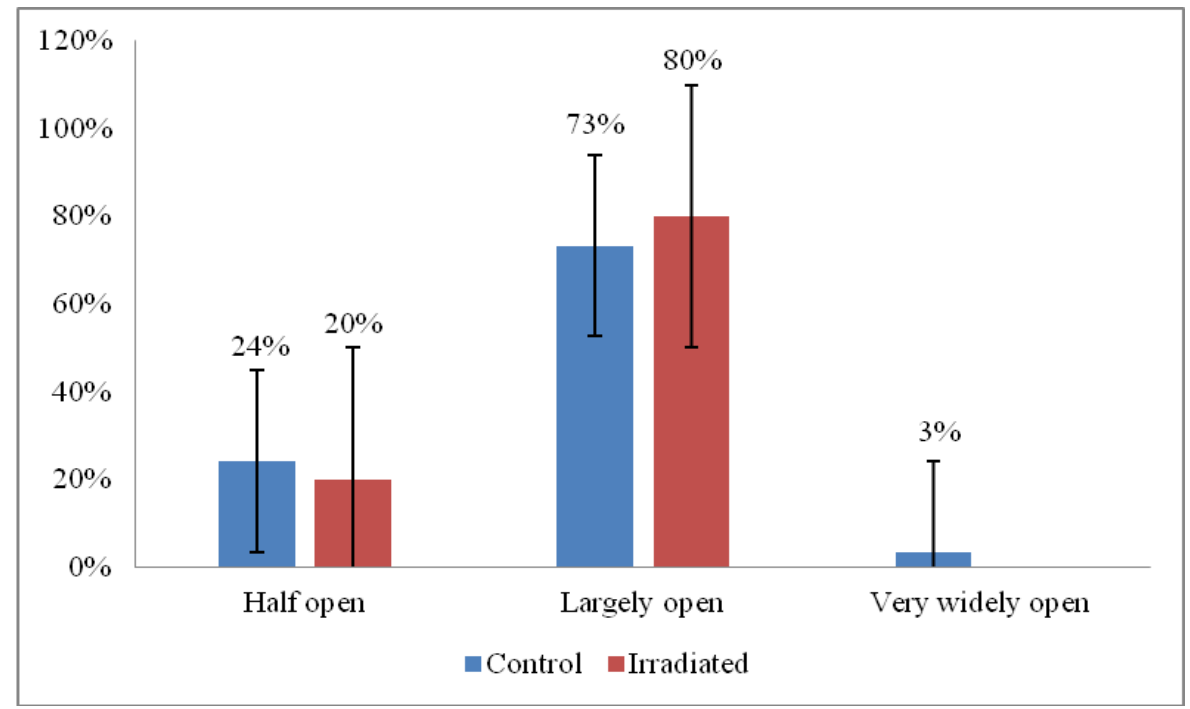

Fig.6. General shape of the petiolar sinus

\subsection{Leaf profile}

The grapevine leaf alone is an excellent organ for determining and classifying species or grape varieties. The following figure shows the leaf profile in irradiated and control grapevine plants. We note a homogeneous

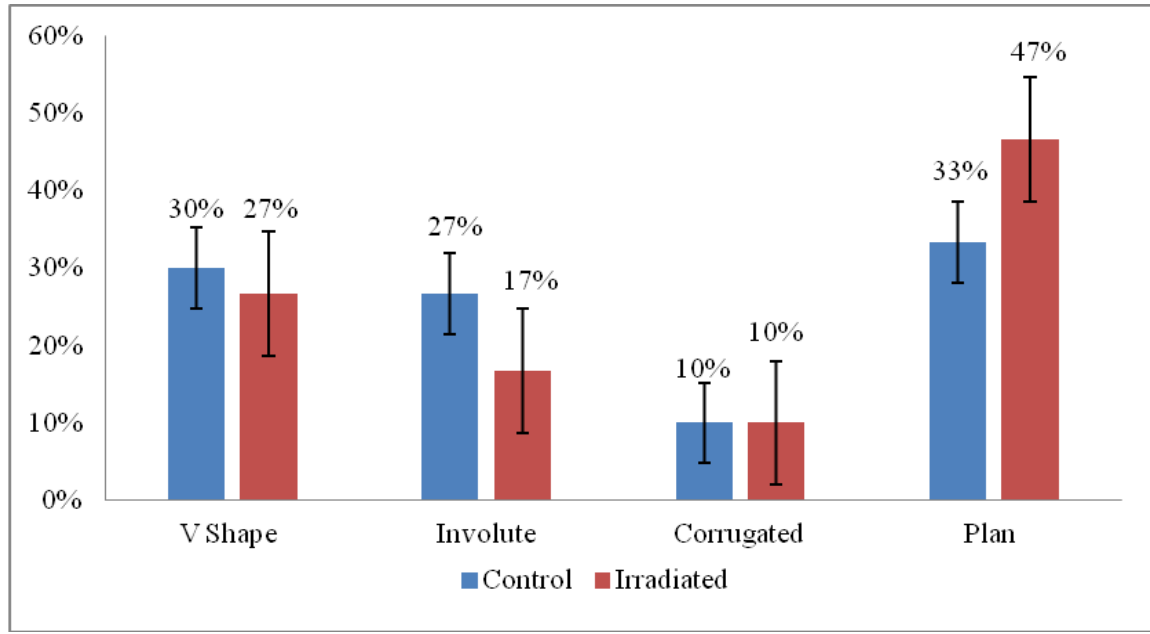

Fig.7. Profile of the sheet at the groups of grapevines irradiated and pilot

\subsection{Upper lateral sinus shape}

The shape of the superior lateral sinus varies according to the group of vines studied. From Figure 9 it is noted that the shape of the upper lateral sinus is open in most varieties and in both control groups and irradiated, also the closed form of the petiole sinus is present in both distribution of the different forms of leaves in the two groups of control and irradiated grapevines. Most of the $47 \%$ irradiated grapes have the shape of flat leaves. Only $10 \%$ of the irradiated and control grape varieties showed a profile of the corrugated sheet.

control forms and irradiated. It was observed that some irradiated grapes $(10 \%)$ showed that the shape of the upper lateral sinus with slightly overlapping lobes. And $3 \%$ of the irradiated varieties showed a form of the lateral sinus superior widely open. These last two forms are absent from the control grapevine groups. 


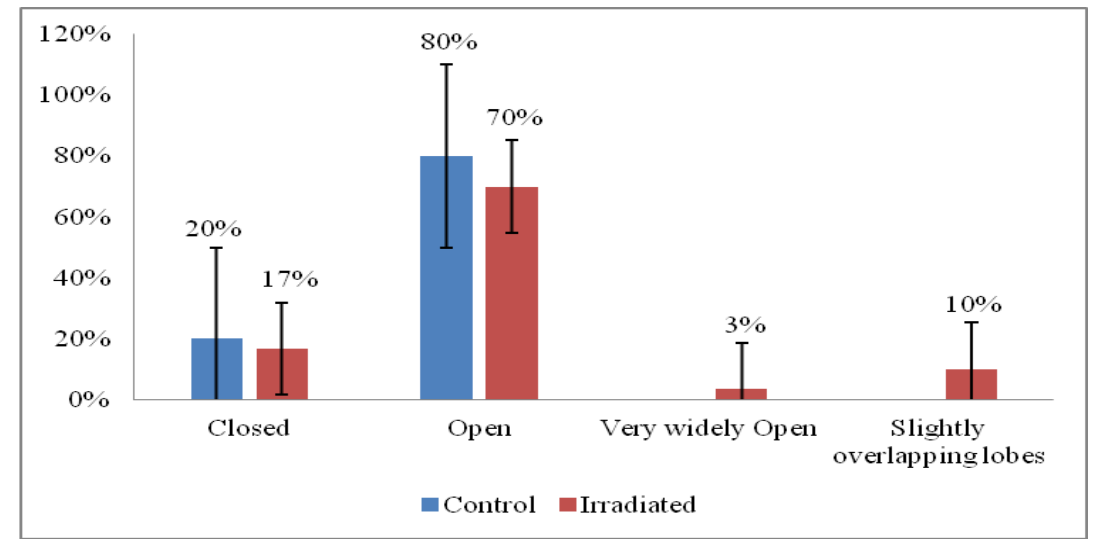

Fig.8. Upper lateral sinus form in control and irradiated groups of grapevines

\section{Villus leaf}

The grapevine is often covered by hairs of different shapes with varying intensity. The villosity of budding corresponds to that of the adult leaf. In fact, everything happens as if the quantity of woolly hairs remained constant during the successive increase of the limb to its final size. Thus the varieties with cottony budding will have leaves whose blade below will be cottony, downy, araneous, according to the initial density of the hairs and the final size of the limb.

\subsection{Density of the coated hairs of the main veins}

A homogeneous distribution of the density of the coated hairs of the main veins in irradiated and control grapevine groups was observed according to Figure 10

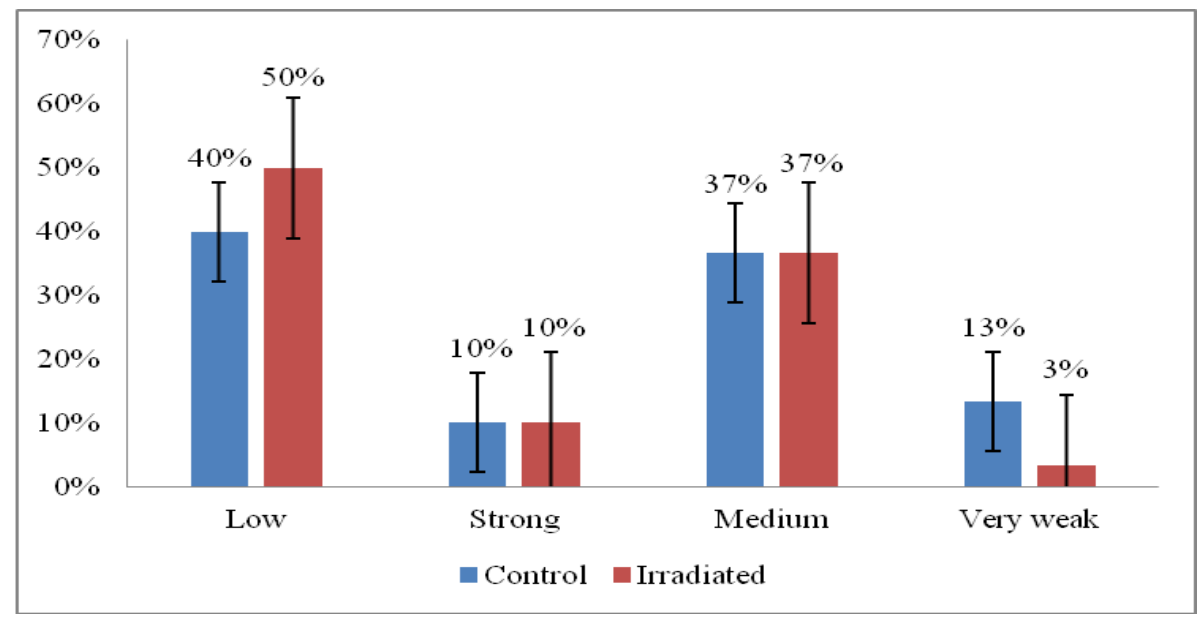

Figure 9: shows a homogeneous distribution of the density of the lungs

\subsection{Density of the hairs lying between the veins}

The following figure shows the distribution of the density of the hairs lying between the veins in irradiated and control vine groups. We observe a homogeneous distribution of the density of the hairs lying between the veins in the two groups. Most irradiated grape varieties showed a dense pile density between the veins, whereas most control grapes showed a low density of hairs lying between the veins. 


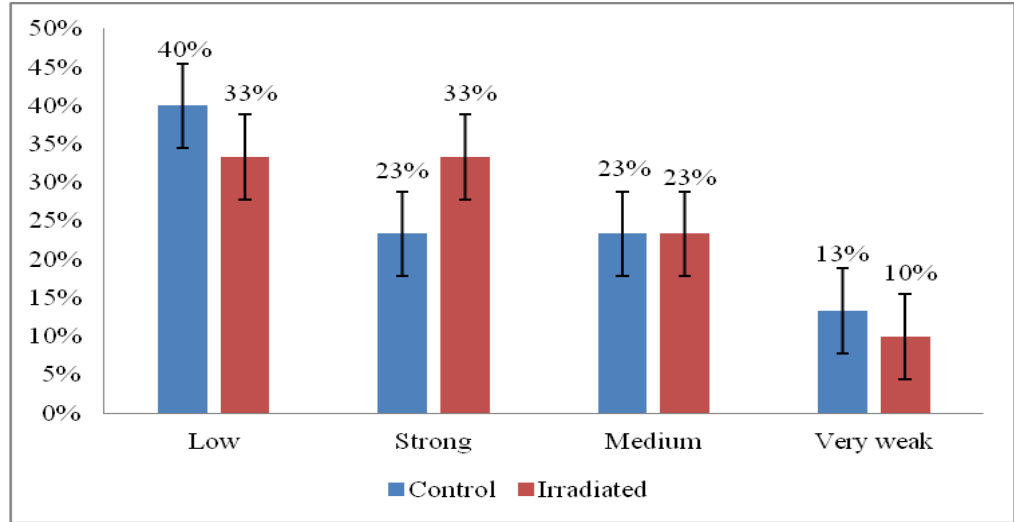

Fig.10. Density of the hairs lying between the veins

\subsection{Density of upright hairs of the main veins}

The following figure shows the density of the upright hairs of the main veins. Most of the irradiated grape varieties $47 \%$ showed a low density of hairs erected from the main veins. The control grape varieties showed a higher density of the primary veins than the irradiated grape varieties.

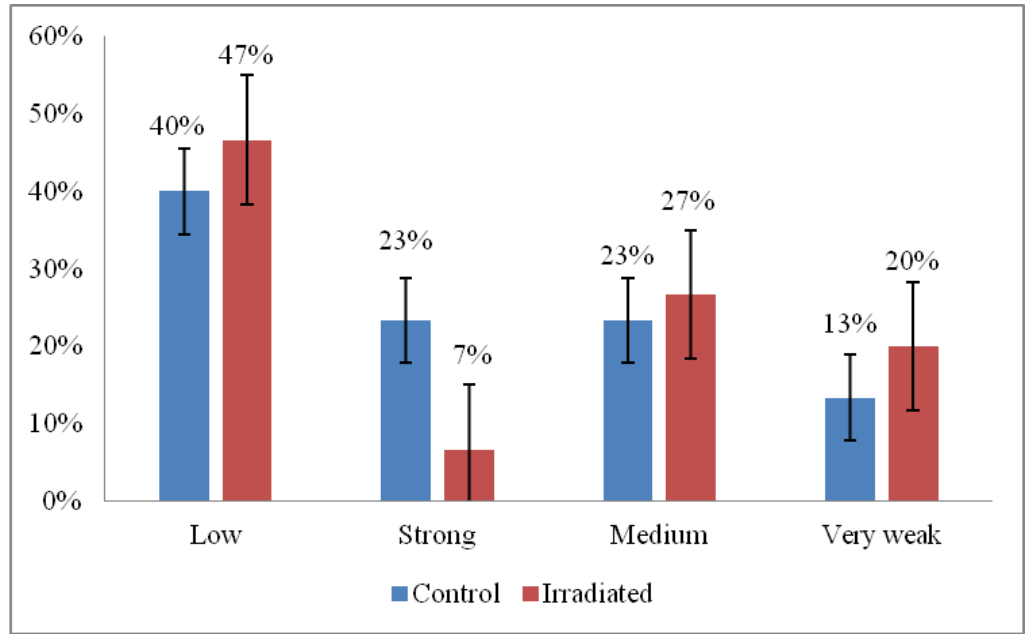

Fig.11. Density of upright hairs of the main veins

\section{Quantitative characteristics}

\subsection{Length of teeth}

The serration is a very good visual ampelographic character, unfortunately very difficult to code, because on the same sheet we find teeth of different shape and unequal depth. Figure 1 shows the variation in tooth lengths in irradiated and control plants. It is noted that the length of teeth in irradiated plants varies between long to medium and never very short, whereas in control plants this length is short and very short.

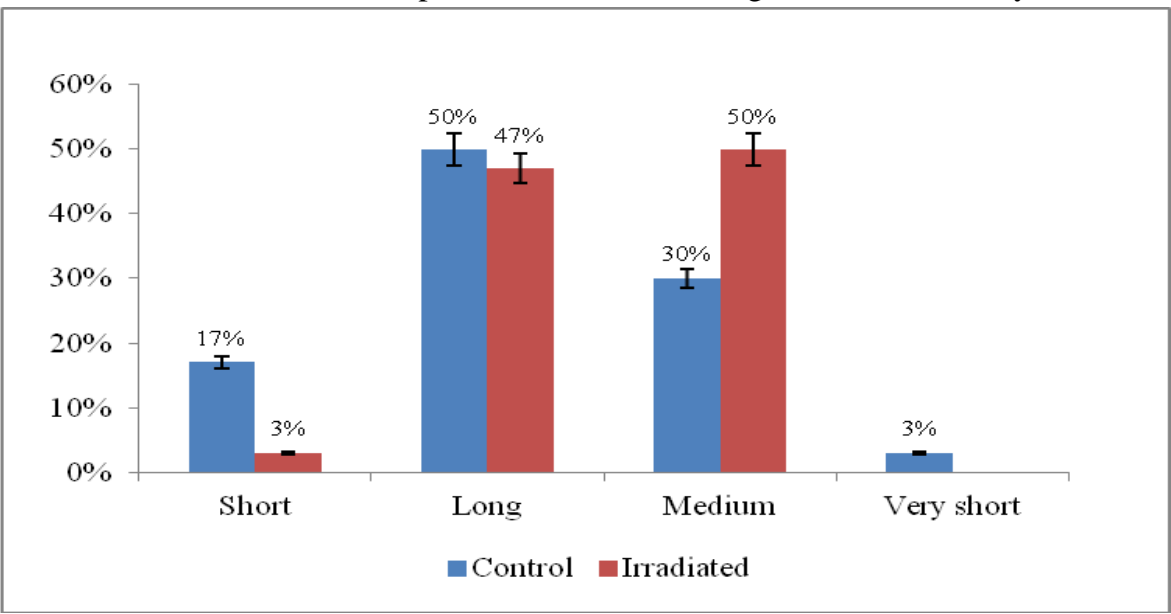

Fig. 12: Length of teeth in irradiated and control grapevines 


\subsection{Length of the tendrils}

The length of the tendrils in control plants varies from 1.5 $\mathrm{cm}$ to $18 \mathrm{~cm}$, whereas in irradiated plants it varies from $2.3 \mathrm{~cm}$ to $15 \mathrm{~cm}$. Most control plants showed a length of tendrils of $6 \mathrm{~cm}$, whereas in irradiated plants most showed a length of tendrils of $9 \mathrm{~cm}$.

\subsection{Length of internodes}

The length of internodes in control plants varies from 2.5 $\mathrm{cm}$ to $8 \mathrm{~cm}$, whereas in irradiated grapevine plants this length varies from $2.5 \mathrm{~cm}$ to $10.5 \mathrm{~cm}$.

\section{Projection the groups in the plan}

Using different qualitative and quantitative parameters we performed a principal component analysis of two groups of grapevine. The result is shown in the following figure.

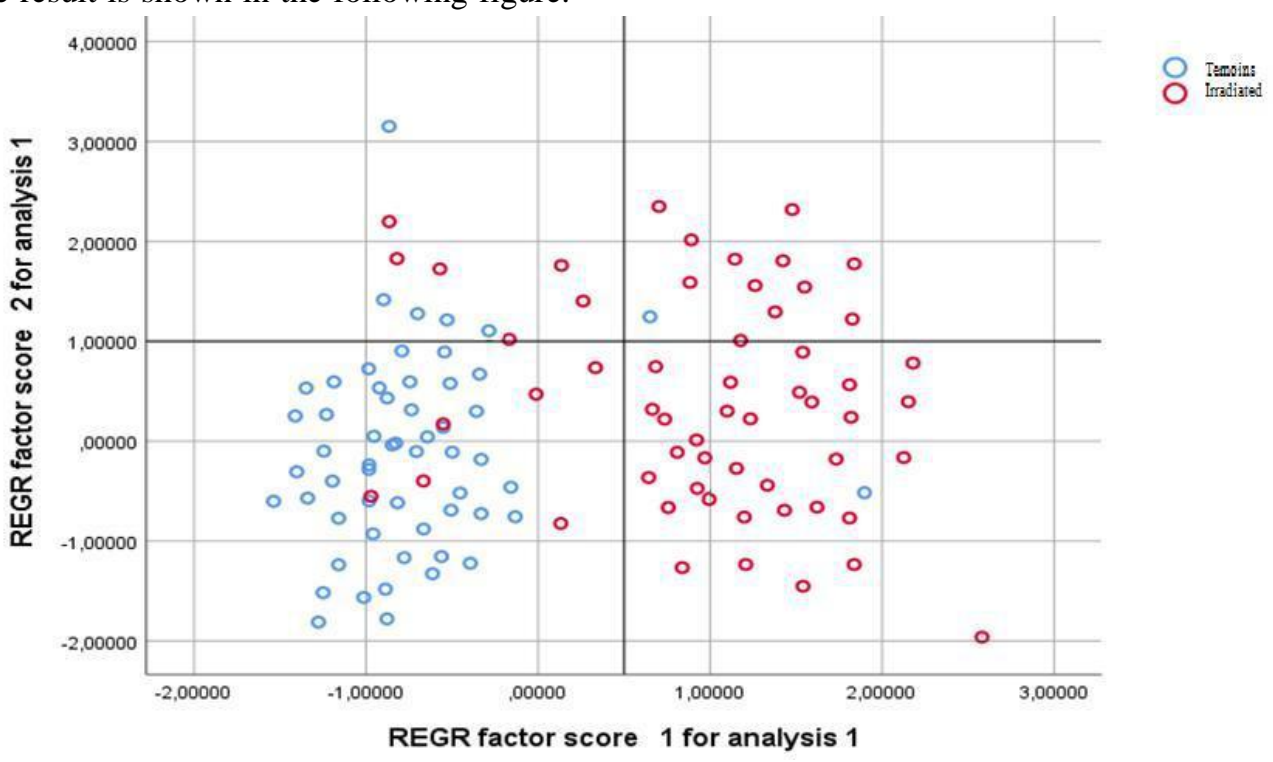

Fig.13: Projection of the groups in the plan $(1,2)$

\section{CONCLUSION}

The different methods used proved very useful for the characterization of mutants and controls of grapevines grown at the Larache experimental area, CRRA Tangier. Classical ampelography is still the method most used in a practical way by a large number of people. The descriptions made on the various organs of the plant remain stable over time and have proved to be very typical and characteristic for each grape variety. Our results motivate the existence of a differentiation between the irradiated and control grapevines and which deserves to be further enlightened with the aid of molecular markers.

\section{REFERENCES}

[1] This P, Lacombe T, Thomas MR. 2006. Historical origins and genetic diversity of wine grapes. Trends in Genetics 22(9): 511-519.

[2] Einset J, Pratt C. 1954. 'giant' sports of grapes. Proc Am Soc Horticult Sci 63(251-256).
We note that the irradiated and control grapevines form two well-distinguished groups.

Some vines of the irradiated group are found in the group of grapevines control the same thing for some grapevines of the control group that are in the group of irradiated grapevines. From the figure that there is a clear differentiation between the two groups of irradiated and control grapevines. This differentiation deserves to be further clarified by studying these individuals in more detail and by using other approaches to differentiate mutants from irradiated ones. 
cultivars preserved in Rioja. Bulletin de L'O.I.V. 793794: 220-230.

[10] Clemente, S. de R (1807) Ensayo sobre las variedades de vid común que vegetan en Andalucia, Madrid.

[11] Viala, P. \& V. Vermorel (1905) Ampélographie. Imp. Masson et Cie, Paris.

[12] Galet, P., (1962) Cépages et vignobles de France. Tome III, Les cépages de cuve (2a partie). Imp. Le Paysan du Midi. Montpellier.

[13] McKey D, Elias M, Pujol B, Duputié A (2009) The evolutionary ecology of clonally propagated domesticated plants. New Phytologist 186 (2): 318-332.

[14] Sbaghi, M (1997) Contribution à l'étude des maladies cryptogamiques de la vigne (Vitis viniféra $L$ ) dans la région de saïs. Rapport-INRA, $78 \mathrm{p}$.

[15] EL Oualkadi A, Sbaghi M, Mouhib M (2018) Application of Mutagenic Radiation and Research the Optimal doses of Induction of bud break and Vegetative Growth in the Grapevine (Vitis vinifera (L.). International Journal of Environment, Agriculture and Biotechnology (IJEAB). Vol-3, Issue-3. ISSN: 2456-1878.

[16] O.I.V (2001) Le code des caractères descriptifs des variétés et espèces de Vitis. O. I. V. (Off. Int. Vigne Vin), Paris.

[17] O.I.V (2007) OIV Descriptor List for Grape Varieties and Vitis Species. O. I. V. (Off. Int. Vigne, Vin), Paris. 